\title{
Stem cells cruise to clinic
}

\section{Japanese study of induced pluripotent stem cells aims to demonstrate safety in humans.}

\section{BY DAVID CYRANOSKI IN TOKYO}

I the seven years since their discovery, induced pluripotent stem (iPS) cells have transformed basic research and won a Nobel prize. Now, a Japanese study is about to test the medical potential of these cells for the first time. Made by reprogramming adult cells into an embryo-like state that can form any cell type in the body, the cells will be transplanted into patients who have a debilitating eye disease.

Masayo Takahashi, an ophthalmologist at the RIKEN Center for Developmental Biology in Kobe, Japan, plans to submit her application for the study to the Japanese health ministry next month, and could be recruiting patients as early as September. Stem-cell researchers around the world hope that if the trial goes forward, it will allay some of the safety concerns over medical use of the cells. And the Japanese government hopes that its efforts to speed iPS cells to the clinic by generously funding such work will be vindicated (see Nature 493, 465; 2013).

"The entire field is very dependent on this group and the Japanese regulatory agencies to ensure that preclinical evidence for safety and efficacy is very strong," says Martin Pera, a stem-cell expert at the University of Melbourne in Australia.

Takahashi, who has been studying the potential of iPS cells to rebuild diseased tissue for more than a decade, hopes to treat around six people who have severe age-related macular degeneration, a common cause of blindness that affects at least $1 \%$ of people aged over 50 . The form of the disease that Takahashi will treat occurs when blood vessels invade the retina, destroying the retinal pigment epithelium that supports the light-sensitive photoreceptors. This form can be treated with drugs that block the growth of new blood vessels, but these often have to be injected repeatedly into the eye.

Takahashi will take a peppercorn-size skin sample from the upper arm and add proteins that reprogram the cells into iPS cells. Other factors will transform the iPS cells into retinal cells. Then a small sheet of cells will be placed under the damaged area of the retina, where, if things go well, the cells will grow and repair the pigment epithelium.

The researchers hope to see the transplants slow or halt the disease, but their main goal is to show that the cells are safe. One concern is that the reprogrammed cells will trigger an immune reaction - as has been seen in mice (T. Zhao et al. Nature 474, 212-215;2011). But that concern has faded after a recent study suggested that iPS cells did not provoke an immune reaction after all (see R. Araki et al. Nature 494, 100-104; 2013 and Nature 493, 145; 2013). "Immune compatibility seems to be as expected, so I am not so concerned about that issue," says stem-cell expert George Daley of Harvard Medical School in Boston, Massachusetts.

A bigger worry is that the reprogrammed

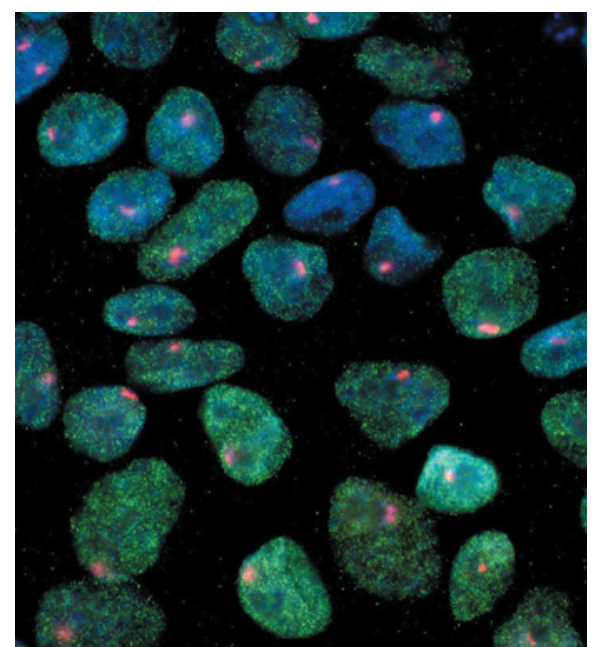

Induced pluripotent stem cells could soon be used in human trials in Japan.

cells might multiply uncontrollably and form tumours instead of healthy tissue. But Pera and Daley are reassured by the pre-clinical data that Takahashi has presented at conferences. Takahashi says that these results, submitted for publication, show that her iPS cells do not form tumours in mice and are safe in non-human primates.

Pera adds that the procedure to treat macular degeneration requires just a few stem cells, reducing the chances that a tumour will form. Also, any tumours would be relatively easy to remove because the eye is more accessible than some organs.

Daley does worry that the treatment, even if it proves harmless, might not be effective. The cells might not engraft properly, for example, or might not integrate with the patients' own tissue. "I think we will require many years of experience to learn more about how cells integrate," he says. Pera raises another concern: that the identity of the cells might not be stable, and that over time they would no longer function as retinal epithelium.

According to Robert Lanza, chief scientific officer at biotechnology firm Advanced Cell Technology (ACT) in Santa Monica, California,
iPS-cell studies like Takahashi's could be premature. "I cannot imagine any regulatory agency permitting such a trial without years of extensive pre-clinical testing," he says. ACT is racing to start a less-ambitious clinical trial of iPS cells for use in other diseases. Its study would inject healthy patients with platelets derived from iPS cells and from embryonic stem cells to see if they act like normal platelets, which could open the way to a treatment for blood-clotting disorders. Because platelets lack a nucleus, there is no risk of forming tumours, explains Lanza. He will meet with the US Food and Drug Administration later this month, and hopes to get approval to start the trial this year.

Lanza says that using iPS cells that contain a nucleus in human trials is "a far greater challenge" than his approach. But Takahashi's team is prepared, counters Pera. They are "among the pioneers in this field", he says, adding that they are "well placed to undertake these studies".

Takahashi is carrying out a 'clinical study' which, in Japan's somewhat confusing system, is less tightly regulated than a clinical trial and cannot by itself lead to approval for clinical use of a treatment. The data, if positive, might attract investors or help Takahashi to get approval for a formal clinical trial — required if the cells are ever to be used to treat patients in the clinic.

The study was approved by institutional review boards at both the natural sciences institute RIKEN in Wako and the Institute of Biomedical Research and Innovation in Kobe, where the surgical procedures will be carried out. Now, approval depends on a health-min-

"The entire field
is very dependent
on this group
and the Japanese
regulatory
agencies."
istry committee of 18 physicians, lawyers, administrators and scientists, including three stem-cell specialists. If Takahashi wins approval by September as expected, it will take another eight months to grow the sheets of cells required for the transplants.

In Japan, future iPS-cell therapies may have an easier path to the clinic as the government continues its drive to capitalize on the technology, which was first developed there. A revised drug law, expected to be put before the Japanese parliament by late June, would fast-track therapies that seem to be effective in phase II or phase III trials. But the success of that drive, and the prospects for patients with macular degeneration, depend in part on Takahashi and her pioneering patients. 